\title{
Psychopathological factors affecting weight loss after bariatric surgery: One year follow-up study
}

Ibrahim TAYMUR ${ }^{1}$, Ersin BUDAK ${ }^{2}$, Naile Ozge OZYURT ${ }^{1}$, Haci Murat $C A Y C l^{3}$, Hakan DEMIRCI $^{4}$, Sinay ONEN ${ }^{1}$

Department of Psichiatry, University of Health Sciences Turkey Bursa Yuksek Ihtisas Training and Research Hospital, Bursa, TURKEY

Department of Clinical Psychology, University of Health Sciences Turkey Bursa Yuksek Ihtisas Training and Research Hospital, Bursa, TURKEY Gastroenterology Surgery, Private Office, Bursa, TURKEY

${ }^{4}$ Department of Family Medicine, University of Health Sciences Turkey Bursa Yuksek ihtisas Training and Research Hospital, Bursa, TURKEY

\begin{abstract}
Aim: Determination of psychopathological factors before bariatric surgery has an important role in successful weight loss and in maintaining this weight loss after surgery. The purpose of this study was to evaluate depression, anxiety, temperament and sociodemographic characteristics that may affect weight loss after bariatric surgery.

Methods: A total of 94 patients with morbid obesity who underwent bariatric surgery between 2013 and 2016 were followed-up for one year. Pre-operative sociodemographic characteristics, binge eating and family history of obesity were determined. In addition, the Memphis, Pisa, Paris and San-Diego Autoquestionnaire (TEMPS-A) for temperament characteristics, the Beck Depression inventory and the Beck Anxiety Inventory were applied.

Results: 94 morbidly obese patients were included in the study. 23(22.8\%) of the patients had failed to lose weight (Excess weight loss $(E W L)<50 \%)$ after 12 months. Participants who had obese siblings $(X 2=$ 4.145, $p=0.042)$ and clinically significant depressive symptoms $(X 2=4.446, p=0.035)$ showed failure to lose weight. According to $\mathrm{BDI}$, it was found that the depressive, cyclothymic, irritable and anxious temperament characteristics of the participants with depression differed significantly compared to those without (respectively; $\mathrm{t}=6.46, \mathrm{p}=<0.001 ; \mathrm{t}=5.59, \mathrm{p}=\langle 0.001 ; \mathrm{t}=4.83, \mathrm{p}=0.001$, respectively; $\mathrm{t}=5.06$, $p=<0.001)$.

Conclusions: It may be important to determine the individuals who have depressive disorder before bariatric surgery and to include practices related to temperament characteristics in their follow-up and treatment. It may be useful to train eating habits and to follow diet programs more closely for those who have obesity among their siblings.
\end{abstract}

Keywords: Bariatric surgery, temperament, depression, weight loss

Corresponding Author: Ersin BUDAK ersin240@hotmail.com

Received: March 18, 2021; Accepted: March 21, 2021; Published Online: April 21, 2021

Cite this article as: Taymur, I., Budak, E., Ozyurt, N., O., Cayci, H., M. \& Demirci, H. (2021). Psychopathological factors affecting weight loss after bariatric surgery: One year follow-up study. European journal of Human Health 1(1), 1-13. 


\section{Introduction}

The effectiveness and prevalence of bariatric surgery have been increasing for the treatment of obesity and comorbid conditions. In individuals with obesity surgery, it is important to maintain an ideal weight for a long time after surgery. It has been found that postoperative feeding behavior and psychological and sociocultural characteristics have an effect on achieving ideal weight loss or maintaining body weight after surgery (1-4).

Temperament includes individual, mostly permanent and invariant structures that define the way people regulate their emotions and behaviors $(5,6)$. Affective temperament characteristics, which include depressive, axiose, irritable, hyperthymic and cyclothymic temperament characteristics, define permanent mood structures that play a role in the continuation of the human species (7). In addition to its positive adaptation mechanism, affective temperament characteristics make a person prone to mental disorders such as mood disorders, substance addiction and eating disorders (8).

In many studies conducted with morbid obese patients who are bariatric surgery candidates, depression and anxiety symptoms, personality disorders and eating disorders are high in these patients and quality of life is impaired (9-12). Although some studies show that there are negative effects on post-operative adaptation and weight loss of depression and anxiety symptoms that are detected before surgery $(13,14)$, other studies show that they are no effects on post-operative weight loss $(12,15)$. These results indicate that there are uncertainties about the effect of preoperative psychopathology on postoperative results. Studies on temperament traits of bariatric surgery candidates are needed to overcome these uncertainties.
Patients undergo a difficult process after bariatric surgery. The personality traits of people are the most important instrument for maintaining harmony in such a difficult period. It has been reported that some personality traits may make this process difficult with inappropriate eating behaviors and disruptive behaviors after surgery. It has also been shown that personality traits may complicate adaptation $(16,17)$. Negative affect, impulsivity, high persistence and selfdirectedness can explain the failure to lose weight after surgery in bariatric surgery candidates (17-19). On the other hand, there are studies reporting that personality traits have no effect on weight loss (2022). Our knowledge on obesity and affective temperament is limited. It is stated that a cyclothymic temperament is dominant in affective temperament properties in morbid obese individuals and it is stated that nutrition behaviors may be impaired with stimulant seeking, self-stimulating behavior and loss of control in individuals with this temperament (23).

The presence of depressive disorder was found to be one of the important negative predictors of weight loss after bariatric surgery (24). There are no studies on the effect of affective temperament, which is one of the biological determinants of depressive disorder, on weight loss after surgery. In our study, we aimed to determine the effect of affective temperament, depression, anxiety and psychosocial features on weight loss after 1 year of follow-up in patients undergoing bariatric surgery.

\section{Participants}

Between November 2013 and February 2017, 286 people were found to be eligible for bariatric surgery in the Bursa Yüksek İhtisas Hospital. Before the operation, 22 participants reported that they no longer planned to have an operation. 264 participants who were operated on were informed about the study and 67 participants were excluded from the study because 
they were not literate. 101 of the 197 individuals who were eligible for participation in the study reported being volunteers. The patients were followed regularly by the general surgery outpatient clinic during the first month, second month, third month, sixth month and first year period.

The criteria for admission to the study, which used a semi-experimental design, was to be at least a primary school graduate, have BMI $\geq 40$, be between the ages of 18-65 and volunteer to participate in the study. Before the study, patients were investigated whether they had any mental illness that prevented them from participating in the study. According to DSM-V criteria, individuals with psychotic, manic or hypomanic attacks in the last year, individuals with alcohol or substance use disorder, and persons with neurodevelopmental disorders were excluded.

In the follow-up period, patients who had inadequate data and were not followed-up were excluded from the study. During the one-year follow-up, 94 people completed the study.

The mean age of the 94 morbidly obese participants, ranging in age from 22 to 56 years, was $35.16 \pm 8.98$, and the mean BMI was $46.33 \pm 5.00 .77(81.9 \%)$ of the participants were women.

\section{Measures}

Sociodemographic data form, Beck Depression Inventory (BDI), Beck Anxiety Inventory (BAI) and TEMPS-A to determine temperament were applied to the participants before the operation. Whether participants had binge eating disorder (according to DSM-V criteria) was determined by psychiatric interview.

On the form of sociodemographic data, age, gender, marital status, education, obesity in parents, obesity in siblings, childhood obesity, additional medical problems (coronary artery disease, vascular disease, diabetes mellitus, hypertension, joint disease), smoking, past psychiatric history, familial psychiatric disease history, past suicidal thoughts and history of past suicidal intervention were questioned.

The Beck Depression Inventory (BDI), which was developed by Beck et al. in 1961 to determine the severity of depressive symptoms in individuals, was adapted to Turkish by Hisli (1988) and its breakpoint was found to be 17 points $(25,26)$. Higher scores on the scale indicate an increase in depressive symptoms and the validity coefficient of the scale is 0.63 . It was found that the scale is a valid and reliable measurement tool in the Turkish population. (26). The Beck Anxiety Inventory (BAI), which was developed by Beck in 1988 to ascertain the severity of anxiety symptoms of individuals, was adapted to Turkish by Ulusoy et al. (1996) and the breakpoint was found to be $17(27,28)$. The correlation coefficients of the scale are between $0.45-0.72$ and the Cronbach a value is 0.93 (28). The higher the score obtained on the scale, the more anxiety the individual is experiencing.

The Memphis, Pisa, Paris and San-Diego Autoquestionnaire (TEMPS-A) is a Likert type of scale developed by Akiskal et al. in 2005 (29). It is a scale used to measure the basic and permanent characteristics that affect the emotional changes seen in individuals with or without bipolar disorder. Its Turkish form and a validity and reliability study were done by Vahip et al. (30). Five sub-temperament features are measured, which are cyclothymic, depressive, hyperthymic, irritable and anxious. The test-re-test reliability of the Turkish translation is between 0.73 and 0.93 , and Cronbach's a coefficient is between 0.75 and 0.84 . Cyclothymic temperament includes emotional fluctuations (I get sudden shifts in mood and energy, my mood often changes for no reason). Depressive temperament includes hopelessness, unhappiness (I am a sad, unhappy person) and lack of energy (I do not seem to have as 
much energy as other people). Hyperthymic temperament includes cheerful, upbeat and enthusiastic features (I am usually in an upbeat or cheerful mood). Irritable temperament contains pessimistic, grumpy, dissatisfied and angry features (I am a grouchy person, I am by nature a dissatisfied person). Anxious temperament includes fear, anxiety (I am often fearful of someone in my family coming down with a serious disease) and somatic complaints (when I am nervous, I often feel nauseous).

The percentage of excess weight loss (EWL\%) and the excess BMI loss (EBMIL\%) were calculated as follows:

EWL\% = (Operative weight -Follow-up weight / Operative excess weight) $\times 100 \%$

The ideal weight was determined using the Metropolitan Life Foundation Height-Weight Charts (29).

EBMIL\% $=$ (pre-operative BMI-current BMI) / (pre-operative BMI - ideal BMI) x $100 \%$

For this formula, a BMI of $25 \mathrm{~kg} / \mathrm{m} 2$ (upper limit of normal BMI) was taken as the ideal BMI.

\section{Procedure}

Volunteer individuals were accepted into the study. A signed consent form was received from all participants before participating in the study. After the evaluation of psychiatric diagnoses, the participants were evaluated individually with a sociodemographic data form and psychometric scales. DSM-V was used to evaluate psychiatric diagnoses. Ethics Committee approval was obtained for the study. In addition, the study was carried out according to the Declaration of Helsinki.

\section{Statistical Analysis}

Chi-square test was used to compare sociodemographic characteristics between the successful and non-successful group after bariatric surgery according to the EWL value. This comparison was made according to sex, education, marital status, past psychiatric history, comorbidities, family obesity status, presence of depression (BDI> 17) and presence of anxiety (BAI> 17). Mann-Whitney $U$ test was used to compare TEMPS-A, BAI, BDI, age and BMI averages between the two groups. Paired Samples $T$ Test was used to examine the 12-month change in BMI averages. The results were reported as odds ratios (ORs) with a 95\% confidence interval (CI). Binomial Logistic Regression analysis was used to evaluate the effectiveness of sociodemographic features, BDI, BAI and TEMPS-A between the successful and non-operative groups. The level of significance was $p<0.05$ for all analyses used in the study and IBM SPSS Statistics 22.0 program was used for the analyses.

\section{Results}

Twenty-nine (30.9\%) of the participants reported that they had received mental treatment in the past, 10 $(10.6 \%)$ of them experienced suicidal ideation in the past and 2 of them $(2.8 \%)$ stated that they attempted suicide in the past. Other sociodemographic characteristics of the participants are shown in Table 1.

After 12 months since laparoscopic sleeve gastrectomy, the mean BMI of the participants decreased to $31.02 \pm 5.63(t=32.18, p<0.001)$, and the mean EWL of the participants was $73.53 \pm 22.44$. According to EWL, 23 (22.8\%) of the patients failed to lose weight (EWL $<50 \%$ ) after laparoscopic sleeve gastrectomy. When sociodemographic characteristics were compared between the two groups who were successful and unsuccessful in weight loss, participants with obese siblings $(X 2=4.145, p=0.042)$ and clinically significant depressive symptoms $(X 2=4.446$, $p=0.035)$ were found to have failed to lose weight (Table 1). 
Table 1: Comparison of sociodemographic characteristics between the successful and unsuccessful groups according to EWL.

\begin{tabular}{|c|c|c|c|c|c|}
\hline & & $\begin{array}{c}\text { UNSUCCESSFUL } \\
\mathrm{n} /(\%)\end{array}$ & $\begin{array}{c}\text { SUCCESSFUL } \\
\mathrm{n} /(\%)\end{array}$ & Chi-square & $\mathrm{p}$ \\
\hline \multirow[t]{2}{*}{ Gender } & Female & $18(78.3)$ & $59(83.1)$ & 0.274 & 0.600 \\
\hline & Male & $5(21.7)$ & $12(16.9)$ & & \\
\hline \multirow[t]{4}{*}{ Education } & $\begin{array}{l}\text { Primary } \\
\text { school }\end{array}$ & $9(39.1)$ & $21(29.6)$ & 0.839 & 0.840 \\
\hline & $\begin{array}{l}\text { Secondary } \\
\text { school }\end{array}$ & $5(21.7)$ & $16(22.5)$ & & \\
\hline & $\begin{array}{l}\text { High } \\
\text { school }\end{array}$ & $6(26.1)$ & $24(33.8)$ & & \\
\hline & University & $3(13)$ & $10(14.1)$ & & \\
\hline \multirow[t]{3}{*}{ Marital status } & Single & $5(21.7)$ & $17(23.9)$ & 1.385 & 0.500 \\
\hline & Married & $15(65.2)$ & $50(70.4)$ & & \\
\hline & Divorced & $3(13)$ & $4(5.6)$ & & \\
\hline \multirow{2}{*}{$\begin{array}{l}\text { Past suicidal } \\
\text { thoughts }\end{array}$} & Yes & $2(8.7)$ & $8(11.3)$ & 0.121 & 0.728 \\
\hline & No & $21(91.3)$ & $63(88.7)$ & & \\
\hline \multirow{2}{*}{$\begin{array}{l}\text { Past suicidal } \\
\text { attempt }\end{array}$} & Yes & $0(0)$ & $2(2.8)$ & 0.662 & 0.416 \\
\hline & No & $23(100)$ & $69(97.2)$ & & \\
\hline \multirow{2}{*}{$\begin{array}{l}\text { Past psychiatric } \\
\text { treatment }\end{array}$} & Yes & $8(34.8)$ & $21(29.6)$ & 0.221 & 0.639 \\
\hline & No & $15(65.2)$ & $50(70.4)$ & & \\
\hline \multirow{2}{*}{$\begin{array}{l}\text { Past psychiatric } \\
\text { treatment in } \\
\text { family }\end{array}$} & Yes & $3(13)$ & $10(14.1)$ & 0.016 & 0.900 \\
\hline & No & $20(87)$ & $61(85.9)$ & & \\
\hline \multirow[t]{2}{*}{ Binge eating } & Yes & $10(43.5)$ & $39(54.9)$ & 0.913 & 0.339 \\
\hline & No & $13(56.5)$ & $32(45.1)$ & & \\
\hline
\end{tabular}


Table 1: Comparison of sociodemographic characteristics between the successful and unsuccessful groups according to EWL. (Continued)

\begin{tabular}{|c|c|c|c|c|c|}
\hline & & $\begin{array}{c}\text { UNSUCCESSFUL } \\
\mathrm{n} /(\%)\end{array}$ & $\begin{array}{c}\text { SUCCESSFUL } \\
\mathrm{n} /(\%)\end{array}$ & Chi-square & $\mathrm{p}$ \\
\hline \multirow{2}{*}{$\begin{array}{l}\text { Childhood } \\
\text { Obesity }\end{array}$} & Yes & $12(52.2)$ & $44(62)$ & 0.692 & 0.405 \\
\hline & No & $11(47.8)$ & $27(38)$ & & \\
\hline \multirow{2}{*}{$\begin{array}{l}\text { Obesity in } \\
\text { siblings }\end{array}$} & Yes & $15(65.2)$ & $29(40.8)$ & 4.145 & 0.042 \\
\hline & No & $8(34.8)$ & $42(59.2)$ & & \\
\hline \multirow[t]{2}{*}{ Maternal obesity } & Yes & $12(52.2)$ & $35(49.3)$ & 0.058 & 0.810 \\
\hline & No & $11(47.8)$ & $36(50.7)$ & & \\
\hline \multirow[t]{2}{*}{ Paternal obesity } & Yes & $8(34.8)$ & $17(23.9)$ & 1.045 & 0.307 \\
\hline & No & $15(65.2)$ & $54(73.4)$ & & \\
\hline \multirow[t]{2}{*}{ Hypertension } & Yes & $7(30.4)$ & $16(22.5)$ & 0.587 & 0.444 \\
\hline & No & $16(69.6)$ & $55(77.5)$ & & \\
\hline \multirow[t]{2}{*}{ Diabetes } & Yes & $6(26.1)$ & $13(18.3)$ & 0.652 & 0.420 \\
\hline & No & $17(73.9)$ & $58(81.7)$ & & \\
\hline \multirow{2}{*}{$\begin{array}{l}\text { Coronary heart } \\
\text { disease }\end{array}$} & Yes & $1(4.3)$ & $2(2.8)$ & 0.132 & 0.717 \\
\hline & No & $22(95.7)$ & $69(97.2)$ & & \\
\hline \multirow[t]{2}{*}{ Vascular disease } & Yes & $5(21.7)$ & $12(16.9)$ & 0.274 & 0.600 \\
\hline & No & $18(78.3)$ & $59(83.1)$ & & \\
\hline \multirow{2}{*}{$\begin{array}{l}\text { Depression } \\
(\mathrm{BDI}>17)\end{array}$} & Yes & $10(43.5)$ & $15(21.1)$ & 4.446 & 0.035 \\
\hline & No & $13(56.5)$ & $56(78.9)$ & & \\
\hline \multirow[t]{2}{*}{ Anxiety(BAI>17) } & Yes & $8(34.8)$ & $23(32.4)$ & 0.045 & 0.832 \\
\hline & No & $15(65.2)$ & $48(67.6)$ & & \\
\hline
\end{tabular}

*Excess Weight Loss (EWL), Beck Depression Inventory (BDI), Beck Anxiety Inventory (BAI)

On the BDI and BAI scales, over 17 points indicates that there are symptoms of depression and anxiety that should be treated clinically. According to the Mann-Whitney $U$ test, it was found that the pre- operative TEMPS-A, BDI, BAI, age and mean BMI were not significantly different between the two groups, those successful or unsuccessful in weight loss (Table 2). 
Table 2: Comparison of preoperative TEMPS-A, BDI, BAI, age and BMI score averages according to operative success.

\begin{tabular}{|c|c|c|c|c|}
\hline & \multicolumn{2}{|c|}{ EWL } & \multirow[t]{3}{*}{$\mathrm{Z}$} & \multirow[t]{3}{*}{$\mathrm{p}$} \\
\hline & Unsuccessful & Successful & & \\
\hline & Mean/Sd & Mean/Sd & & \\
\hline BDI & $14.86 \pm 9.30$ & $13.08 \pm 7.22$ & -0.687 & 0.492 \\
\hline BAI & $13.26 \pm 11.55$ & $13.63 \pm 10.19$ & -0.387 & 0.698 \\
\hline $\begin{array}{l}\text { Depressive } \\
\text { temperament }\end{array}$ & $7.60 \pm 3.40$ & $6.80 \pm 3.02$ & -0.844 & 0.399 \\
\hline $\begin{array}{l}\text { Cyclothymic } \\
\text { temperament }\end{array}$ & $8.86 \pm 5.58$ & $8.67 \pm 4.55$ & -0.097 & 0.923 \\
\hline $\begin{array}{l}\text { Hyperthymic } \\
\text { temperament }\end{array}$ & $10.73 \pm 3.75$ & $11.66 \pm 3.88$ & -1.228 & 0.219 \\
\hline Irritable temperament & $4.00 \pm 3.83$ & $3.74 \pm 3.48$ & -0.022 & 0.982 \\
\hline Anxious temperament & $7.60 \pm 5.16$ & $6.52 \pm 4.32$ & -0.609 & 0.542 \\
\hline Age & $37.16 \pm 9.38$ & $35.92 \pm 6.88$ & -0.409 & 0.682 \\
\hline BMI & $48.53 \pm 6.95$ & $45.58 \pm 4.02$ & -1.931 & 0.054 \\
\hline
\end{tabular}

*Excess Weight Loss (EWL), Beck Depression Inventory (BDI), Beck Anxiety Inventory (BAI), Body Mass Index (BMI)

Participants with obesity among siblings (95\% CI, 1.01-7.23; $\mathrm{p}=0.04$ ) failed to lose weight after laparoscopic sleeve gastrectomy. People with symptoms of depression that required clinical intervention failed to lose weight 2.8 times more often (95\% CI, 1.05-7.82; $\mathrm{p}=0.03)$ after bariatric surgery (Table 3).

Table 3: The effect of depression and having an obese sibling on the success of surgery.

\begin{tabular}{|l|l|l|l|l|l|l|}
\hline & & Unsuccessful & Successful & Odds ratio & $95 \%$ CI & $\mathrm{p}$ \\
\hline $\begin{array}{l}\text { Having an } \\
\text { obese } \\
\text { sibling }\end{array}$ & Yes & $15(65.2)$ & $29(40.8)$ & 2.71 & $1.01-7.23$ & 0.045 \\
\hline $\begin{array}{l}\text { Depression } \\
(\text { BDI>17) }\end{array}$ & Yes & $10(43.5)$ & $15(21.1)$ & 2.87 & $1.05-7.82$ & 0.039 \\
\hline & No & $13(56.5)$ & $56(78.9)$ & & & \\
\hline
\end{tabular}


Binary logistic regression showed that sociodemographic features, BDI, BAI and TEMPS-A did not add significantly to the model (Table 4). The explained variation in the dependent variable based on the model ranged from $12.5 \%$ to $18.6 \%$, depending on whether it referenced the Cox \& Snell R2 or
Nagelkerke R2 methods, respectively. Therefore, the model explained $18.6 \%$ (Nagelkerke R2) of the variance in EWL and correctly classified $78.7 \%$ (Overal Percentage) of cases.

Table 4 Predictors of a good outcome (\%EWL $>50 \%$, categorical variable) binary logistic regression adjusted to sociodemographic features, BDI, BAI and TEMPS-A

\begin{tabular}{|c|c|c|c|c|c|c|c|c|}
\hline & $\mathrm{B}$ & SE & $x^{2}$ & $d f$ & $p$ & OR & \multicolumn{2}{|c|}{$95 \% \mathrm{CI}$} \\
\hline & & & & & & & LL & UL \\
\hline Constant & -0.871 & 1.376 & 0.400 & 1 & 0.527 & 0.419 & & \\
\hline Female & -0.572 & 0.740 & 0.596 & 1 & 0.440 & 0.565 & 0.132 & 2.409 \\
\hline $\begin{array}{l}\text { Past psychiatric treatment in } \\
\text { family (Yes) }\end{array}$ & 0.692 & 0.911 & 0.577 & 1 & 0.448 & 1.998 & 0.335 & 11.910 \\
\hline Past psychiatric treatment (Yes) & 0.373 & 0.612 & 0.371 & 1 & 0.542 & 1.452 & 0.438 & 4.816 \\
\hline Binge eating (Yes) & -0.819 & 0.596 & 1.885 & 1 & 0.170 & 0.441 & 0.137 & 1.419 \\
\hline Childhood obesity (Yes) & -0.787 & 0.647 & 1.482 & 1 & 0.223 & 0.455 & 0.128 & 1.617 \\
\hline Obesity in siblings (Yes) & 0.995 & 0.635 & 2.458 & 1 & 0.117 & 2.705 & 0.780 & 9.384 \\
\hline Maternal obesity (Yes) & -0.261 & 0.616 & 0.179 & 1 & 0.672 & 0.771 & 0.230 & 2.577 \\
\hline Paternal obesity (Yes) & 0.598 & 0.644 & 0.861 & 1 & 0.353 & 1.818 & 0.515 & 6.422 \\
\hline BDI & 0.016 & 0.054 & 0.092 & 1 & 0.761 & 1.017 & 0.914 & 1.130 \\
\hline BAI & -0.035 & 0.041 & 0.709 & 1 & 0.400 & 0.966 & 0.891 & 1.047 \\
\hline Depressed temperament & 0.049 & 0.172 & 0.081 & 1 & 0.776 & 1.050 & 0.750 & 1.471 \\
\hline Cyclothymic temperament & 0.027 & 0.104 & 0.069 & 1 & 0.793 & 1.028 & 0.838 & 1.261 \\
\hline Hyperthymic temperament & -0.042 & 0.075 & 0.311 & 1 & 0.577 & 0.959 & 0.828 & 1.111 \\
\hline Irritable temperament & -0.005 & 0.114 & 0.002 & 1 & 0.964 & 0.995 & 0.796 & 1.244 \\
\hline Anxious temperament & 0.056 & 0.103 & 0.295 & 1 & 0.587 & 1.057 & 0.865 & 1.293 \\
\hline
\end{tabular}


Depressive $(t=6.46, p<0.001)$, cyclothymic $(t=5.59$, $\mathrm{p}<0.001)$, irritable $(\mathrm{t}=4.83, \mathrm{p}<0.001)$ and anxious $(t=5.86, p<0.001)$ temperament score averages were found to differ between individuals with and without depression according to BDI. According to the BAI, the mean of depressive $(t=3.77, p<0.001)$, cyclothymic $(t=5.01, p<0.001)$, irritable $(t=4.99, p<0.001)$ and anxious $(t=6.04, p<0.001)$ temperament scores was different between individuals with and without depression (Table 5).

Table 5: Comparison of temperament characteristics among people with and without depression; with and without anxiety.

\begin{tabular}{|l|c|c|c|c|c|c|c|c|}
\hline & $\mathrm{BDI}>17$ & $\mathrm{BDI} \leq 17$ & & & $\mathrm{BAI}>17$ & $\mathrm{BAI} \leq 17$ & & \\
\hline & $\mathrm{n}=30)$ & $(\mathrm{n}=64)$ & & & $(\mathrm{n}=33)$ & $(\mathrm{n}=61)$ & & $\mathrm{p}$ \\
\hline $\begin{array}{l}\text { Depressive } \\
\text { Temperament }\end{array}$ & $9.53 \pm 2.47$ & $5.81 \pm 2.65$ & 6.46 & $<0.001$ & $8.54 \pm 2.92$ & $6.16 \pm 2.91$ & 3.77 & $<0.001$ \\
\hline $\begin{array}{l}\text { Cyclothymic } \\
\text { temperament }\end{array}$ & $12.23 \pm 3.63$ & $7.07 \pm 4.39$ & 5.59 & $<0.001$ & $11.72 \pm 3.64$ & $7.09 \pm 4.57$ & 5.01 & $<0.001$ \\
\hline $\begin{array}{l}\text { Hyperthymic } \\
\text { temperament }\end{array}$ & $10.76 \pm 3.69$ & $11.75 \pm 3.9$ & -1.15 & 0.251 & $12.63 \pm 3.30$ & $10.78 \pm 3.99$ & 2.27 & 0.025 \\
\hline $\begin{array}{l}\text { Irritable } \\
\text { temperament }\end{array}$ & $6.13 \pm 4.34$ & $2.71 \pm 2.49$ & 4.83 & $<0.001$ & $6.03 \pm 3.66$ & $2.60 \pm 2.87$ & 4.99 & $<0.001$ \\
\hline $\begin{array}{l}\text { Anxious } \\
\text { temperament }\end{array}$ & $9.86 \pm 4.62$ & $5.34 \pm 3.73$ & 5.06 & $<0.001$ & $10.06 \pm 4.81$ & $5.01 \pm 3.24$ & 6.04 & $<0.001$ \\
\hline $\begin{array}{l}\text { Age } \\
\text { Agean }\end{array}$ & $34.88 \pm 8.47$ & $35.59 \pm 9.2$ & -0.33 & 0.740 & $32.43 \pm 8.66$ & $36.94 \pm 8.88$ & - & 0.026 \\
\hline BMI & $47.09 \pm 5.12$ & $45.93 \pm 4.9$ & 1.04 & 0.300 & $45.61 \pm 3.97$ & $46.68 \pm 5.50$ & - & 0.327 \\
\hline
\end{tabular}

Beck Depression Inventory (BDI), Beck Anxiety Inventory (BAI)

\section{Discussion}

In current study, it was found that $77.2 \%$ of the participants had reached the expected weight loss at one year follow-up after sleeve gastrectomy surgery and were successful in weight loss. When the successful and unsuccessful groups in weight loss were compared, it was found that the TEMPS-A, BDI and BAI scales did not differ between the two groups.
It has been reported that some personality traits may make this process difficult with inappropriate eating behaviors and disruptive behaviors after surgery. It has also been shown that personality traits may complicate adaptation $(16,17)$. Negative affect, impulsivity, high persistence and self-directedness can explain the failure to lose weight after surgery among 
bariatric surgery candidates (17-19). The result of current study was that the temperament characteristics of obese individuals did not have an effect on weight loss after bariatric surgery. Today, the personality pattern is considered to be composed of sub-components of character and temperament. Temperament is defined as the innate, more biological basis of behavioral tendencies. Character is defined as the way a person develops with the social environment and learning, to perceive the world and to cope with life (31). Therefore, in our study, only studying the effect of temperament properties on weight loss, not other sub-components of personality, may have led to the results. On the other hand, there are studies reporting that personality traits have no effect on weight loss (20-22).

Although some studies report that there are negative effects on post-operative adaptation and weight loss of depression and anxiety symptoms that are detected before surgery $(13,14)$, other studies show that they are no effects on post-operative weight loss $(12,15)$. In the current study, it was determined that patients who had high BDI scores in the preoperative period could not reach the expected weight loss in the postoperative period and therefore failed to lose weight. It is very important that patients with severe depressive symptoms before the operation receive preoperative treatment and that these therapies continue after the operation. On the other hand, in the current study we compared the temperament characteristics of the participants who were clinically depressive and not based on the low weight loss success of the participants who were clinically depressed. It was found that cyclothymic, depressive, irritable and anxious temperament were statistically significantly higher in those with clinical depression. In a meta-analysis study investigating the temperament properties of patients with major depressive disorder, the data of 8 studies were evaluated (32). The results of our study showed a significant similarity to the results of the meta-analysis. A consistent relationship between mood disorders and temperament, which was established by Akiskal, has been shown in many studies (33-35). The results of depressive symptom severity and affective temperament characteristics of morbid obese patients are consistent with Akiskal's theory. The relationship between obesity, mood disorders and temperament characteristics has been recently elucidated. Previous studies have found that cyclothymic, anxious and irritable temperament properties predominate in patients with morbid obesity (23). Amman et al. (2009) found significant abnormal temperament characteristics in morbid obese patients who applied for obesity surgery compared to the control group. They stated that cyclothymic temperament is especially important in these patients. In our study, the relationship between depressive symptoms and temperament characteristics in morbid obese patients are consistent with Akiskal's theory. The predominance of these temperament characteristics in morbid obese patients may be related to the resistance of depressive symptoms. Having clinically significant depressive symptoms adversely affects the functionality of individuals, leads to loss of motivation and causes reluctance to lose weight $(36,37)$. In addition, depression is associated with hormonal dysregulation, immune system disorders and metabolic problems $(38,39)$. Therefore, obese people with depressive symptoms may fail to lose weight.

Another important finding we found in our study was the high rate of obesity in the siblings of patients who had weight loss failure after sleeve gastrectomy. Negative beliefs and behaviors related to nutrition in the family beginning at early ages, and difficulties in changing these beliefs and behaviors by changing conditions (diet, exercise, bariatric surgery) may be related to the presence of obesity among siblings. 
One of the main limitations of our study was the small number of patients. Also, the fact that the depression and anxiety levels of the patients were determined by scales, not with psychiatric interviews, is one of the main limitations of the study. Patients may have hid their psychiatric complaints in order to obtain consent for bariatric surgery. Therefore, higher levels of depression and anxiety may be present in these patients, and this may have influenced the results. Another limitation was that the individuals who participated in the study had not been followed-up in terms of compliance with these training programs, even though they were informed about pre- and postoperative nutrition training, diet and exercise. The lack of written documents and data for questioning childhood obesity is an important limitation. This information was completed with the patients' statements and information from their families and this may have reduced the reliability of the data.

\section{Conclusions}

There is no significant difference between the temperament characteristics of individuals with respect to successful weight loss after bariatric surgery. Preoperative depressive disorder and presence of obesity in siblings are important factors affecting successful weight loss after bariatric surgery. Cyclothymic, depressive, irritable and anxious temperament were found to be significantly higher in people with clinically significant depression, and depression is one of the important negative predictors of weight loss. Considering these statements, further studies are recommended on this subject.

\section{Conflict of interest}

The authors declare that there is no conflict of interest.

\section{References}

1. Wimmelmann $\mathrm{CL}$, Dela $\mathrm{F}$, Mortensen $\mathrm{EL}$. Psychological predictors of mental health and health-related quality of life after bariatric surgery: a review of the recent research. Obes Res Clin Pract. 2014 Jul-Aug;8(4):e314-24. doi: 10.1016/j.orcp.2013.11.002.

2. White B, Doyle J, Colville S, Nicholls D, Viner RM, Christie D. Systematic review of psychological and social outcomes of adolescents undergoing bariatric surgery, and predictors of success. Clin Obes 2015 Dec;5(6):312-24. doi: 10.1111/cob.12119

3. Willcox K, Brennan L. Biopsychosocial outcomes of laparoscopic adjustable gastric banding in adolescents: a systematic review of the literature. Obes Surg 2014 Sep;24(9):1510-9. doi: 10.1007/s11695-014-1273-3.

4. Dilektasli E, Erol MF, Cayci HM, Ozkaya G, Bayam ME, Duman U, Tihan ND, Erdogdu U, Kisakol G. Low educational status and childhood obesity associated with insufficient mid-term weight loss after sleeve gastrectomy: a retrospectiveobservational cohort study. Obes Surg. 2017 Jan;27(1):162-168. doi: $10.1007 / \mathrm{s} 11695-016-2273-2$

5. Sanson, A., Hemphill, S. A., \& Smart, D. (2004). Connections between temperament and social development: A review. Social Development, 13(1), 142-170.

6. Cloninger, C. R., Svrakic, D. M., \& Przybeck, T. R. (1998). A psychobiological model of temperament and character. The development of psychiatry and its complexity, 1-16.

7. Akiskal, K. K.,\& Akiskal, H. S. (2005). The theoretical underpinnings of affective temperaments: implications for evolutionary foundations of bipolar disorder and human nature. Journal of affective disorders, 85(1-2), 231-239.

8. Rihmer, Z., Akiskal, K. K., Rihmer, A., \& Akiskal, H. S. (2010). Current research on affective temperaments. Current opinion in psychiatry, 23(1), 12-18.

9. Abilés $V$, Rodríguez-Ruiz $S$, Abilés J, Mellado $C$, García A, Pérez de la Cruz A, Fernández-Santaella MC. Psychological characteristics of morbidly obese candidates for bariatric surgery. Obes Surg 2010 Feb;20(2):161-7. doi: 10.1007/s11695-008-9726-1 
10. van Hout GC, van Oudheusden I, van Heck GL. Psychological profile of the morbidly obese. Obes Surg 2004 May;14(5):579-88. doi: $10.1381 / 096089204323093336$

11. Mauri M, Rucci $P$, Calderone $A$, Santini $F$, Oppo A, Romano A, Rinaldi S, Armani A, Polini M, Pinchera A, Cassano GB. Axis I and II disorders and quality of life in bariatric surgery candidates. J Clin Psychiatry 2008 Feb;69(2):295-301.

12. Powers PS, Rosemurgy A, Boyd F, Perez A. Outcome of gastric restriction procedures: weight, psychiatric diagnoses, and satisfaction. Obes Surg 1997 Dec;7(6):471-7. doi: $10.1381 / 096089297765555197$

13. Herpertz S, Kielmann R, Wolf AM, Hebebrand J, Senf W. Do psychosocial variables predict weight loss or mental health after obesity surgery? A systematic review. Obes Res 2004 Oct;12(10):1554-69. doi: 10.1038/oby.2004.195

14. Scholtz S, Bidlake L, Morgan J, Fiennes A, El-Etar $A$, Lacey $\mathrm{JH}$, et al. Long-term outcomes following laparoscopic adjustable gastric banding: postoperative psychological sequelae predict outcome at 5-year follow-up. Obes Surg 2007; 17(9):12205.

15. Sheets CS, Peat CM, Berg KC, White EK, BocchieriRicciardi L, Chen EY, Mitchell JE. Post-operative psychosocial predictors of outcome in bariatric surgery. Obes Surg 2015 Feb;25(2):330-45. doi: 10.1007/s11695-014-1490-9

16. Glinski J, Wetzler S, Goodman E. The psychology of gastric bypass surgery. Obes Surg 2001; 11: 581-8. doi: 10.1381/09608920160557057

17. De Panfilis C, Generali I, Dall'Aglio E, Marchesi F, Ossola P, Marchesi C. Temperament and one-year outcome of gastric bypass for severe obesity. Surg Obes Relat Dis 2014 Jan-Feb;10(1):144-8. doi: 10.1016/j.soard.2013.09.018

18. Gordon PC, Sallet JA, Sallet PC. The impact of temperament and character inventory personality traits on long-term outcome of Roux-en-Y gastric bypass. Obes Surg 2014 Oct;24(10):1647-55. doi: 10.1007/s11695-014-1229-7.

19. Leombruni P, Piero A, Dosio D, et al. Psychological predictors of outcome in vertical banded gastroplasty: a 6 months prospective pilot study. Obes Surg 2007;17:941-8.

20. Larsen JK, Geenen $R$, Maas $C$, de Wit $P$, van Antwerpen $\mathrm{T}$, Brand $\mathrm{N}$, van Ramshorst $\mathrm{B}$. Personality as a predictor of weight loss maintenance after surgery for morbid obesity.
Obes Res 2004 Nov;12(11):1828-34. doi: $10.1038 /$ oby. 2004.227

21. Black DW, Goldstein RB, Mason EE. Psychiatric diagnosis and weight loss following gastric surgery for obesity. Obes Surg 2003 Oct;13(5):746-51. doi: $10.1381 / 096089203322509327$

22. Barrash J, Rodriguez EM, Scott DH, Mason EE, Sines JO. The utility of MMPI subtypes for the prediction of weight loss after bariatric surgery. Minnesota Multiphasic Personality Inventory. Int J Obes 1987;11(2):115-28.

23. Amann, B., Mergl, R., Torrent, C., Perugi, G., Padberg, F., El-Gjamal, N., Laakmann, G. Abnormal temperament in patients with morbid obesity seeking surgical treatment. J. Affect. Disord. 2009;118, 155-60. doi: 10.1016/j.jad.2009.01.020

24. Van Hout, G. C., Verschure, S. K., \& Van Heck, G. L. (2005). Psychosocial predictors of success following bariatric surgery. Obes Surg, 15(4), 552560.

25. Beck AT, Ward $\mathrm{CH}$, Mendelson $\mathrm{M}$, et al. An inventory for measuring depression. Arch Gen Psychiatry 1961;4:561-71.

26. Hisli N. Beck depresyon envanterinin geçerliliği üzerine bir çalışma. Psikoloji Dergisi 1988;6:11822.

27. Beck AT, Epstein N, Brown G, et al. An inventory for measuring clinical anxiety: psychometric properties. J Consult Clin Psychol 1988;56:893897.

28. Ulusoy $M$, Şahin $\mathrm{NH}$, Erkmen $\mathrm{H}$. Turkish version of the Beck Anxiety Inventory: Psychometric properties. Journal of Cognitive Psychotherapy 1998;12:163-72.

29. Akiskal HS, Akiskal KK, Haykal RF, Manning JS, Connor PD. TEMPS-A: progress towards validation of a self-rated clinical version of the Temperament Evaluation of the Memphis, Pisa, Paris, and San Diego Autoquestionnaire. J Affect Disord 2005;85: 3-16. doi:10.1016/j.jad.2004.12.001

30. Vahip S, Kesebir S, Alkan M,et al. Affective temperaments in clinically-well subjects in Turkey: initial psychometric data on the TEMPSA. J Affect Disorders 2005;85:113-125. doi:10.1016/j.jad.2003.10.011

31. Cloninger, C. R., Svrakic, D. M., \& Przybeck, T. R. (1998). A psychobiological model of temperament and character. The development of psychiatry and its complexity, 1-16 
32. Papakostas GI, Petersen T, Iosifescu DV, Burns AM, Nierenberg AA, Alpert JE, Rosenbaum JF, Fava M. Obesity among outpatients with major depressive disorder. Int ] Neuropsychopharmacol 2005 Mar;8(1):59-63. doi: $10.1017 / \mathrm{S} 1461145704004602$

33. Akiskal, H. S. (1996). The temperamental foundations of affective disorders. Interpersonal factors in the origin and course of affective disorders, 3-30

34. Akiskal, H. S.,\& Akiskal, K. (1992). Cyclothymic, hyperthymic, and depressive temperaments as subaffective variants of mood disorders. American psychiatric press review of psychiatry

35. Rihmer, Z., Akiskal, K. K., Rihmer, A., \& Akiskal, H. S. (2010). Current research on affective temperaments. Current opinion in psychiatry, 23(1), 12-18.
36. Smith, B. (2013). Depression and motivation. Phenomenology and the Cognitive Sciences, 12(4), 615-635

37. Whitton, A. E., Treadway, M. T., \& Pizzagalli, D. A. (2015). Reward processing dysfunction in major depression, bipolar disorder and schizophrenia. Current opinion in psychiatry, 28(1), 7

38. Masih, J.,\& Verbeke, W. (2018). Immune System Function and its Relation to Depression: How Exercise can Alter the Immune System-Depression Dynamics

39. Gold, P. W. (2015). The organization of the stress system and its dysregulation in depressive illness. Molecular psychiatry, 20(1), 32 